\title{
Addendum \\ Addendum: Rehnelt et al. Frequency-Dependent Multi-Well Cardiotoxicity Screening Enabled by Optogenetic Stimulation. Int. J. Mol. Sci. 2017, 18, 2634
}

\author{
Susanne Rehnelt ${ }^{1}$, Daniela Malan ${ }^{1}$, Krisztina Juhasz ${ }^{2,+} \mathbb{D}$, Benjamin Wolters ${ }^{3}$, Leo Doerr ${ }^{2}$, Matthias Beckler ${ }^{2}$, \\ Ralf Kettenhofen ${ }^{3}$, Heribert Bohlen ${ }^{3}$, Tobias Bruegmann $1,4, *, \mp$ (D) and Philipp Sasse ${ }^{1, * \mathbb{D}}$ \\ 1 Institute of Physiology I, Medical Faculty, University of Bonn, 53127 Bonn, Germany; \\ s4surehn@uni-bonn.de (S.R.); dmalan@uni-bonn.de (D.M.) \\ 2 Nanion Technologies GmbH, 80636 Munich, Germany; krisztina.juhasz@nanion.de (K.J.); \\ leo.doerr@nanion.de (L.D.); matthias.beckler@nanion.de (M.B.) \\ 3 Part of the Ncardia Group, Axiogenesis AG, 50829 Cologne, Germany; benjamin.wolters@ncardia.com (B.W.); \\ ralf.kettenhofen@ncardia.com (R.K.); heribert.bohlen@ncardia.com (H.B.) \\ 4 Research Training Group 1873, University of Bonn, 53127 Bonn, Germany \\ * Correspondence: tobias.bruegmann@med.uni-goettingen.de (T.B.); philipp.sasse@uni-bonn.de (P.S.); \\ Tel.: +49-(0)228-73-2402 (P.S.) \\ + Present address: Institute for Nanoelectronics, Department of Electrical Engineering and Information \\ Technology, Technische Universität München, 80333 Munich, Germany. \\ $\ddagger$ Present address: Institute for Cardiovascular Physiology, University Medical Center Goettingen, \\ 37073 Goettingen, Germany.
}

check for updates

Citation: Rehnelt, S.; Malan, D.; Juhasz, K.; Wolters, B.; Doerr, L.; Beckler, M.; Kettenhofen, R.; Bohlen, H.; Bruegmann, T.; Sasse, P.

Addendum: Rehnelt et al. Frequency-Dependent Multi-Well Cardiotoxicity Screening Enabled by Optogenetic Stimulation. Int. J. Mol. Sci. 2017, 18, 2634. Int. J. Mol. Sci. 2021, 22, 5562. https://doi.org/ $10.3390 /$ ijms 22115562

Received: 9 March 2021

Accepted: 15 March 2021

Published: 25 May 2021

Publisher's Note: MDPI stays neutral with regard to jurisdictional claims in published maps and institutional affiliations.

Copyright: (c) 2021 by the authors. Licensee MDPI, Basel, Switzerland. This article is an open access article distributed under the terms and conditions of the Creative Commons Attribution (CC BY) license (https:// creativecommons.org/licenses/by/ $4.0 /)$.
The authors would like to indicate that the commercial human cardiomyocytes used in the study (Cor.4U@, NCardia/Axiogenesis AG, Cologne, Germany) [1] were believed to be derived from human induced pluripotent stem cells during the studies. After the studies had been completed and published, short tandem repeat testing by NCardia determined that Cor.4U@ cardiomyocytes revealed the genetic background of the human embryonic stem cell line RUES2. The different provenience of these well-characterized cardiomyocytes changes neither our findings nor the interpretation of our data.

Conflicts of Interest: The authors declare no conflict of interest.

\section{Reference}

1. Rehnelt, S.; Malan, D.; Juhasz, K.; Wolters, B.; Doerr, L.; Beckler, M.; Kettenhofen, R.; Bohlen, H.; Bruegmann, T.; Sasse, P. Frequency-Dependent Multi-Well Cardiotoxicity Screening Enabled by Optogenetic Stimulation. Int. J. Mol. Sci. 2017, 18, 2634. [CrossRef] [PubMed] 